\title{
Communicative Competence of the Saudi Learners of English at the Faculty of Languages and Translation, King Khalid University
}

\author{
Rafiq Ali Mohamed Al-Shamiry \\ Faculty of Languages and Translation, King Khalid University, KSA
}

\begin{abstract}
Saudi students of English at the tertiary level King Khalid University, encounter so many difficulties in real communicative situations due to the influence of the traditional methods of teaching English at the intermediate and secondary schools. The researcher conducted a questionnaire consists of eight questions in order to find out the main difficulties of the learners. The sample of the pilot study was ten students and the actual population of the study was ninety students from level four and eight. The learners' responses indicate that they lack the needed skills of communication strategies which usually lead to communication breakdown. For example, they change the topic when they feel there are some gaps in their speech. This literally means that students resort to risk-avoiding instead of risk-taking. The findings of the study point out the extent to which the Saudi students' first language influences their tendency of using some of the target language communication strategies. It is recommended that the linguistic competence should be taught implicitly whereas the functional competence should be taught explicitly during spoken English classes which may compensate for their lack of exposure to the target language.
\end{abstract}

Index Terms - communicative competence, communication strategies, communication breakdown, lack of exposure

\section{INTRODUCTION}

One of the main difficulties of the Saudi learners of English when they join the Faculty of Languages and Translation at King Khalid University is their lack of oral proficiency. Students can hardly understand simple questions, let alone answering them. Their reading and writing abilities are much better than their listening and speaking. This indicates clearly that students did not get enough practice of the spoken language during their studies at the intermediate and secondary schools. The textbooks used at these stages obviously do not help the learners to communicate in English in daily life situations. Students do not have any formal oral tests during their studies at the intermediate and secondary schools. As a result of this negligence at the early stages of their studies, students encounter many problems at the tertiary level in listening and speaking.

This paper attempts to shed lights into the main problems of the Saudi learners' oral proficiency and to suggest some solutions to help the learners to overcome their difficulties in listening and speaking.

\section{HYPOTHESES}

The researcher hypothesizes that there is a correlation between:

1. Students' low oral proficiency and lack of communication strategies,

2. Students' low oral proficiency and lack of exposure to the target language and its culture.

\section{BASIC RESEARCH QUESTIONS:}

Which of the following factors affect the Saudi learners' communicative competence most and lead to communication breakdown?

1. Lack of communication strategies.

2. Lack of exposure to the target language and its culture.

\section{LITERATURE REVIEW}

By early nineteen eighties a change in the second language pedagogy gave birth to the Communicative Approach which was a revolution against the traditional approaches. It aims at developing the learners' communicative competence. In other words, it is mainly concerned with developing the communicative ability in language learners. Howatt (1984) indicates that the original motivation for developing a Communicative Approach was remedial, an attempt to overcome the inadequacies of existing structural syllabi, materials and methods. However, the recent 
approach is organized on the basis of communicative functions. It does not ignore the role of grammar in the process of language teaching but questions the usefulness of grammatical rules without their application to real life situations.

\section{CHARACTERISTICS OF THE COMMUNiCATIVE APPROACH}

The goal of Communicative Approach is to make learners communicatively competent. Of course, this has been the stated goal of many of the traditional methods, but in the Communicative Approach the notion of what it takes to be communicatively competent is much extended.

Communicative competence involves being able to use the language appropriately in a given social context. To do this, students need knowledge of the linguistic forms, meaning, and functions. Dorney and Thurell 1997, p.141-152

The term "Communicative Competence" was coined by Dell Hymes (1972) a sociolinguistic who was convinced that Chomsky's (1965) notion of competence was limited. In view of Chomsky's (1965) strong claim that that competence is to be associated exclusively with a knowledge of the rules of grammar, Hymes (1972) proposed a broader notion of competence, that of 'Communicative Competence'. This notion intends to include not only grammatical competence (implicit and explicit knowledge of the rules of grammar) but also context or sociolinguistic competence (implicit and explicit knowledge of the rules of language use). He is (ibid) of the view that there are rules of grammar that would be useless without rules of language use (Hymes 1972, p, 141-161).

\section{Definition of Communicative Competence}

Richard's (1992:65) defines Communicative Competence as:

The ability not only to apply the grammatical rules of a language in order to form grammatically correct sentences but also to know when and where to use these sentences and to whom.

Ellis (1994) indicates that:

Communicative competence includes knowledge that speaker - hearer has of what constitutes appropriate as well as correct language behavior and also of what constitutes effective language behavior in relation to particular communicative rules.

Savignon (1983:87) is of the view that:

Communicative Competence is relative, not absolute, and depends on the cooperation of all the participants involved.

According to Canale and Swain (1980) and later in Canale (1983) definition, four different components or subcategories make up the construction of communicative competence. The first two subcategories reflect the use of the linguistic system itself. "Grammatical Competence" is that aspect of communicative competence that encompasses knowledge of lexical items and rules of morphology, syntax, sentence-grammar semantics, and phonology. It is the competence that we associate with mastering the linguistic code of a language or the "Linguistic Competence". The second subcategory is "Discourse Competence" the complement of grammatical competence in many ways. It is the ability to connect sentences in stretches of discourse and to form a meaningful whole out of a series of utterances. In other words, it focuses on discourse of supra-sentential (above the sentence) level - those properties of language which bind the sentences together such as coherence; whereas grammatical competence focuses on sentence level grammar.

The last two subcategories define more functional aspects of communication. "Sociolinguistic Competence" is the knowledge of sociocultural rules. This type of competence requires an understanding of the social context in which language is used by participants, the information they share and the functions of the interaction. They are concerned with style, register, appropriateness (degree of politeness) and so on.

The fourth subcategory is "Strategic Competence". Canale and Swain (1980:40) describe strategies competence as:

The verbal and nonverbal Communicative Strategies that may be called into action to compensate for breakdown in communication due to performance variable or due to insufficient competence.

The components of communicative competence can be illustrated as follows:

1. Grammatical competence

2. Discourse competence

3. Sociolinguistic competence

4. Strategic competence

\} Linguistic Competence

\} Functional Competence

Though communicative Approach came as a reaction against the traditional methods and sought to improve learners' Communicative Competence, it can be noted that more and more materials in modern course books are designed to develop 'Linguistic Competence' in the learners. On the other hand, ' Strategic Competence' which is regarded as the most important element in communication is utterly neglected. Therefore, learners' Communicative Competence cannot be improved merely by developing some of its components (i.e. Grammatical Competence and Discourse Competence) which represent the linguistic system. Thus, activating strategic competence is of crucial importance of foreign 
language learners. Researchers in this field indicate that lack of strategic competence my account for situation when students get stuck and are unable to carry out their communicative intent.

Nunan (1987:136) has pointed out this phenomenon, he says:

While a great deal has been written on the theory and practice of communicative language teaching, there have been comparatively few studies of actual communicative language practice.

\section{DEFINITION OF STRATEGIC COMPETENCE}

One of the problems has occupied researchers of CSs from the beginning concerns the identification of CSs. This issue is still controversial to date. Poulisse (1994) indicates that of all definitions of CSs that have been offered so far, the one by Faerch and Kasper (1983) is the most widely used. They define CSs as "Potential conscious plans for solving what presents itself as a problem in reaching a particular communicative goal". In this definition problem-orientedness is adopted as a primary and potential consciousness as a secondary criterion. In practice, this means that CSs can be identified when speakers are aware of a problem in their communication.

Ugla (2019) indicates that the speakers use strategic competence to communicate smoothly and fluently through FL. The importance of strategic competence is to work with the strategic knowledge verbally and non-verbally to compensate for failures. For instance: a speaker corrects himself and at the same time strengthens his communication ability. Oral communication is always known as communication strategies.

Al Alawi (2016) indicates that "Among Arab speaking students in Oman, it has been observed that many learners struggle while communicating in English They cannot express their ideas or interact with other people freely. Many of them are very hesitant to communicate because of their inadequate competence in the target language".

Selinker (1972) coined the term "Communication Strategies" (CSs) in his seminal paper on "Interlanguage", discussing strategies of second language "Communication" as one of the five central processes involved in L2 learning. However, it was Varadi (1992) who first empirically studied this phenomenon, namely, "Strategies of target language learner communication". In 1973, he presented a paper at a small European conference on "Message Adjustment" in which he considered the first systematic analysis of strategic language behavior. But that paper was not published till 1980. In the seventies, Tarone, Cohen and Dumas (1976), Tarone (1977) published two studies on CS is which they provide the first definition of CS as well as the first lexical taxonomy.

Richards (1992:354) defines strategic competence:

An aspect of communicative competence which describes the ability of speakers to use verbal and non-verbal communication strategies to compensate for breakdown in communication or to improve the effectiveness of communication. For example, a learner may lack a particular word or structure and may have to use a paraphrase or circumlocution to compensate.

This indicates that, communication strategies are the means of strategic competence; and that the use of strategy is called for only when the learner faces some problems in a communicative situation. Varadi (1992:137) points out that "the original insight into communication strategies was based on a mismatch between communicative intention and linguistic resources." This implies that communication strategies are used only when a speaker perceives that there is a problem which might interrupt communication.

In fact, strategies competence occupies a special place in understanding communication. It is the way we manipulate language in order to achieve our communicative goals. Paribakht (1985) conducted an empirical study in which she investigated the Strategic Competence in relation to language proficiency. Poulisse, 1996 compared native and nonnative speakers' Communicative Strategies (CS) used in a task which required the subjects to describe concrete and abstract concepts (e.g., palanquin and hammock verses fate and honesty). The study involved 60 subjects 20 native speakers of English, and two groups of 20 Iranian learners of English. The difference between the types of CS used by the three groups was minimal. The groups did differ, however, in the relative frequency with which they used a number of CS types. In comparison with advanced learners and native speakers, initial learners made more use of their knowledge of the world and of paralinguistic knowledge (i.e., mime and gestures) when they had to compensate for the limitations of their linguistic knowledge. This led Paribakht to conclude that CS use and L2 proficiency level are related.

Chen (1990:156) states that:

One can develop learners' communicative competence by building up their strategic competence that is their ability to use communication strategies that allow them to cope with various communication problems that they might encounter.

Chen (ibid) conducted a study on 12 Chinese learners to explore the relationship between learners' language proficiency and their Strategic Competence. He adopted a concept-identification task as the communicative task. There were 24 concepts 12 concrete and 12 abstracts; each concept within the concrete and abstract category had the same difficulty level. Each subject was required to communicate two concrete and two abstract concepts from the 24 to a native speaker interlocutor in an interview situation. The subjects were asked to convey the items to the native speakers, who did not know which concepts were being transmitted - without using the exact target words so that they were 
forced to make use of CSs. The native speaker's task was to identify the concept and at the same time to rank the communicativeness of the strategy used to convey each concept. The major findings were:

1. The frequency of the CSs employed by the Chinese EFL learners in their target language communication was found to vary according to their proficiency level. The CSs employed by the low-proficiency learners significantly outnumbered those employed by the high proficiency learners.

2. The relative frequency with which Chinese EFL learners selected different types of CSs in their target language communication was found to vary according to their proficiency level. Linguistic-based CSs were more frequently employed by the high-proficiency learners whereas knowledge-base and repetition CSs were more extensively used by the low-proficiency learners.

3. A positive relationship was found between the Chinese EFL learners' proficiency level and their communicative effectiveness. High-proficiency learners were more efficient in their use of CSs than were low-proficiency learners.

4. Not only the language proficiency, but also the language distance between the learners' L1 and L2 was found to affect their choice of CSs. No obvious L1-based CSs were employed by Chinese EFL learners of both high and low proficiency due to lack of formal similarity between the learners' L1 (Chinese) and L2 (English).

So far, the most comprehensive study of CS is the one conducted by the University of Nijmegen (Poulisse 1990). The Nijmegen project was set up to investigate the proficiency effect, the relationship between CS use in L1 and L2 and the effectiveness of various CS types. Only compensatory strategies were studied.

Rabab'ah (2016) is of the view that:

Second/foreign language learners' speaking ability is sometimes interrupted by a gap in their linguistic knowledge. In trying to fill the gap, they employ communication strategies to keep the conversation going. If they fail to do so successfully, this gap may cause frustration breakdown. Research has shown that both native and non-native speakers of English employ communication strategies, but non-native speakers use them more frequently due to their limited linguistic sources.

According to Nakatani (2010:118), the term oral communication strategy is used to "highlight interlocutors' negotiation behavior for coping with communication breakdowns and their use of communication enhancers".

Rabab'ah (2005) suggests that learners of the foreign/second language should be exposed to variety of tasks and activities to enhance their communicative ability and that should be integrated into ELT syllabus.

Littlewood (1981) is of the view that:

Learners must draw on a wider range of skills and strategies in order to new meanings across. There is a gradual increase in the range of communicative functions that are likely to occur. Learners also need to develop greater skills for managing the interaction, e.g., signaling disagreement or interrupting without offence. There is increasing opportunity for learners to express their own individuality in discussion.

Faucette (2001) is of the view that communication strategies need to be taught such as circumlocution, paraphrase and approximation to enable the learners to keep the channel of the communication open. Similarly, Dornyei and Scott (1997) recommended teaching five interaction strategies (appeal for help, asking for repetition, clarification request, confirmation request, and guessing), which can help the learners to negotiate the meaning with their interlocutors.

Dornyei (1995) indicates that the real career of CSs started in the early eighties when Varadi published his article "Strategic of Target Language Learner Communication: Message Adjustment". Then followed by Canale and Swain (1980): Canale (1983), Faerch and Kasper (1983a) published and edited volume, "Strategies in Interlanguage Communication", which pulled together the most important published papers on CSs at that time. Many publications appeared focusing primarily on identifying and classifying CSs. The most important research on CSs appeared in the second half of 1980s at the University of Nijmegen (Netherlands). The results of that research shed light on various aspects of CSs use and challenged some aspects of the previous taxonomies.

Bialystok (1990) and Pouliss's (1990) researches were another important contribution in the field of CSs.

Finally, the second half of the 1990s brought further empirical and conceptual analyses of the teachability of CSs which is introduced as a new dimension in the field of second language teaching.

\section{TYPOLOGIES OF CSS}

Faerch and Kasper (1983) classify communication strategies into three major types:

1. Formal reduction strategies

2. Functional strategies and

3. Achievement strategies.

\section{1) Formal reduction strategies}

These are strategies by learners to avoid producing non-fluent or incorrect utterances. Using such strategies, learners focus on the use of specific, limited rules or patterns that they can perfectly master. The purpose of utilizing these strategies, which deal with linguistic aspects of the target language, i.e., phonology, morphology, syntax and lexis, is to avoid errors and to facilitate speech.

2) Functional reduction strategies: 
These strategies are used when the learners have experienced problems in the planning phase (due to insufficient linguistic resources) or the execution phase (retrieval problems). The aim of such strategies is to avoid rather than to achieve.

\section{3) Achievement Strategies:}

Whereas the previous two kinds of strategies are to solve communication problems using avoidance, achievement strategies make use of communication resources expansion. They are used both in the planning and executive phase. Achievement strategies used in planning phase are called compensatory strategies. They are classified as follows:

a) Code switching: Tarone, Cohen and Dumas (1983) refer to it as language switch. This means a change by a speaker from one language or variety to another one. It can take place in a conversation when one speaker uses one language and the other speaker answers in a different language. A person may start speaking one language and then change to another one in the middle of their speech or sometimes even in the middle of a sentence.

b) Interlanguage transfer: It is similar to code switching but rather it includes the shift to a combination of linguistic features of the native language and the Interlanguage. Here, the learner combines a word in their native language with a word in the foreign language that has similar spelling or pronunciation but with different meaning. For example, the Danish word "history" which means "story" may be matched with the English word "history".

c) Inter-intralingual transfer: This strategy includes overgeneralization of grammatical rules. For example, the words "people" and "information" will be pluralized as "peoples*" and "informations* which means the learner did not master the exceptions of the grammatical rules of the target language.

d) Interlanguage-based strategies: These are strategies affected by problems that learners face in their interlanguage system. To solve these problems, learners may use 'generalization, paraphrase, and/or word coinage (using new words of the individual's own to express what that individual wants to say, e.g., "inner clothes" for "underwear").

e) Cooperative strategies: Such strategies are used when learners fail to communicate successfully, and ask for help from the listener, the teacher, a friend and so on.

f) Non-linguistic strategies: In face to face communication, the learners may use non-verbal mime, gesture, and signals.

Whereas achievements strategies aiming at solving problems at the planning phase are called compensatory strategies, achievement strategies used to overcome obstacles in the execution phase are retrieval strategies. The retrieval strategies are categorized in Faerch and Kasper (1983) as follow:

1. Waiting for the term to appear, appealing to/formality, retrieving via semantic fields, searching via other language, retrieving form learning situations and sensory procedures.

1) Avoiding communication

2) Adjust the message

3) Use paraphrase

4) Use approximation

5) Create new words

6) Switch to the native language

7) Use non-linguistic resources

8) Seek help

He (ibid) suggests that when the learner is aware of gaps or weaknesses in his linguistic repertoire and when he feels that others are competing for turns, he chooses to avoid participating in the discussion of the topic. When the learner cannot avoid participating, he may choose to adjust the message to the linguistic resources available to him. For example, he may omit some information which he is unable to express or may express it less precisely by slightly changing the meaning. He may also describe a word or a concept for which he does not know the target language expression, which is called paraphrase. For example, if he does not know the word "kettle" he may use a definition such as "a thing we boil water in". In place of the word, sometimes the learner may use a word or a phrase which is very close to the target language expression (the strategy of approximation). For example, if the learner wants to refer to a "water-pipe" but does not know the word, then he may call it a "pipe".

Corder (1983:104-106) points out that all strategies used by learners fall under two macro-strategies. They are:

1. Message adjustment or risk-avoidance or 
2. Resource expression or risk-running strategies.

He maintains that when the learner is faced with a situation where his linguistic resources do not permit him to express himself successfully the learner has only two options open for him. He can either tailor/adjust the message to the linguistic resources available to him (the strategy of message adjustment) or he can attempt to increase his resources by one means or another in order to realize his communicative intentions (the strategy of resource expansion).

In message adjustment the learner either refuses to enter into or continue a discourse with some field or topic because of a total linguistic inadequacy (which is called strategy of topic avoidance or he tries but give up or says something slightly different from what was intended. These are message abandonment and semantic avoidance strategies respectively. Here the learner compromises on the message. In resource expansion the learner attempts to increase his resources by one way or another I order to realize his communicative intentions rather than compromise on the intended message.

\section{The EFFECt of CSS on Oral Communicative Competence}

There is little agreement on the role CSs should play in foreign language classrooms. Some people have propagated the view that learners should receive explicit instruction as to what CSs are and what kind of CSs they could use.

Research on effects of this kind of direct instruction is scant and contradictory; some investigators claim that learner's communicative abilities were greatly improved after they received instruction in CSs use. For example, Savignon (1972), who calls them "coping strategies", Buch (1989), Chen (1990) Rost and Ross (1991), Dornyei and Thurrell (1991), Dornyei and Thurrell (1991), Dornyei and Thurrell (1994), Dornyei (1995), Dornyei and Scott (1977).

Other investigators have argued that there is no need to explicitly teach CSs since second language (L2) learners who generally know how and when to use CSs in their first language (L1) are able to transfer their strategic competence to L2 situations. They know what kind of descriptions to give to unknown words and know that transfer strategies are likely to be successful. Thus, L2 learners do not so much need to develop their strategic competence, but rather need to learn how to perform it.

Chen (1990) rejects the idea that Strategic Competence is transformable from L1 to L2. His argument is that learners employ CSs every now and then, but may not be able to use the appropriate CSs spontaneously. Dornyei (1995) supports Chen's point of view when he argues that learners come to the L2 classroom with the skill of "reading" in their L1. So why do we have to teach them to read in the target language since they have already acquired the skill?

O'Mally (1987:143) provides some evidence for the teachability of strategic competence. He indicates that: Teachers should be confident that there exist a number of strategies which can be embedded into their existing curricula, that can be taught to student with only modest extra effort, and that can improve the overall class performance... Future research should be directed to refining the strategy training approaches, identifying effects associated with individual strategies, and determining procedures for strengthening the impact of the strategies on student outcomes.

O'Malley and Chamot (1990:184) emphasizes that learning strategy training should be direct, that is "students should be appraised of the goal of strategy instruction and should be made aware of the strategies they are being taught". Oxford 1990 supports the idea of direct strategy training. She says:

Research shows strategy training which fully informs the learners (by indicating why the strategy is useful, how it can be transferred to different tasks, and how learners can evaluate the success of this strategy) is more successful than training that does not. Oxford (1990, p.207).

Chen (1990) agrees with Faerch and Kasper (1983) that strategic competence could be taught explicitly in the L2 classroom. He sees that it is possible to do something about our teaching method to make it conducive to the development of learners' Strategic Competence. That means teaching the learners how to use CSs appropriately and effectively as part of the classroom syllabus. Bialystok (1983) argues that strategy training could enable them to recognize particular communicative problems and employ particular CSs, which are the most effective ones to solve these problems.

Rost and Ross (1991) support the idea of teaching CSs explicitly. They came to this conclusion from their study of using CSs for teaching listening comprehension to a group of learners "Identification - task strategies". Their findings indicate that the strategies they implemented in their study are highly teachable.

Some studies did investigate the potential usefulness of the specific training of CSs, and provide evidence that explicit instruction can increase both the quality and quantity of communicative competence.

\section{PioneER Studies In CSS TRAining}

Savignon (1972) was one of the pioneers in this field. She seems to have realized that the mastery of the mechanics of a language did not ensure the ability use of the language of communication. She also observed that the traditional teaching practice did not help or lead to authentication. Therefore, she started to think of the possibility of creating authenticity in second language teaching in the classroom. That means producing some materials for teaching verbal 
exchange based on real life situations. That means producing some materials for teaching verbal exchange base on real life situations. She was concerned mainly with the skills that are needed to get ones' meaning across, to do things in the second language, to say what one really wants to say. She conducted an experiment in which she studied the communicative skills and grammar skills of three groups of college students enrolled in and introductory audio-lingual French Course in the United States. All three groups received the same number of hours of instruction in the standard (formal and grammatical) program, but one group had an additional hour to a "culture lab" program and the third spent an additional hour in a language laboratory program. We will refer to these groups as the communicative competence (CC) group, the culture group, and grammatical competence group.

She found that although there was no significant difference among groups on tests of grammatical competence, the 'CC' group scored significantly higher than the other two groups on four communicative tests she developed. Savignon's finding was that students who had received training in communicative skills felt better prepared to use their limited knowledge of French to (its best) advantage. Freed from an overt concern with linguistic accuracy; they were able to communicate in French whereas the other control groups were not.

Buch (1989) observed that some learners manage to participate in the target language communicative situations, whereas the majority fail though they have more or the same socio-economic, educational and linguistic to use the language for communication. She also observed that he traditional teaching practice did not help or lead to authentic communication. Therefore, she started to think of the possibility of creating authenticity in second language teaching in the classroom. That means producing some materials for teaching verbal exchange based on real life situations. She was concerned mainly with the skills that are needed to get ones' meaning across, to do things in the second language, to say what one really wants to say. She conducted an experiment in which she studied the communicative skills and grammar skills of three groups of college students enrolled in an introductory audio-lingual French Course in the United States. All three groups received the same number of hours of instruction in the standard (formal and grammatical) program, but one group had an additional class-hour per week devoted to communicative tasks (where the emphasis was mainly on getting one's meaning across). The second group got an additional hour to a "culture lab" program and the third spent an additional hour in a language laboratory program. WE will refer to these groups as the communicative competence (CC) group, the culture group, and grammatical competence group.

She found that although there was no significant difference among groups on tests of grammatical competence, the 'CC' group scored significantly higher than the other two groups on four communicative tests she developed.

Savignon's finding was that students who had received training in communicative skills felt better prepared to use their limited knowledge of French to (its best) advantage. Freed from an overt concern with linguistic accuracy; they were able to communicate in French whereas the other control groups were not.

Buch (1989) observed that some learners manage to participate in the target language communicative situations, whereas the majority fail though they have more or less the same socio-economic, education and linguistic background and almost the same linguistic repertoire. Therefore, she conducted a study to develop the ability of using CSs in learners who were inhibited from using CSs (and thus, fail to participate in TL communicative situations). In her study, she prepared a set of activities on the assumption that in performing those activities learners would resort to various CSs. However, I order to find out whether they contribute to the development of use of CS, a 14-day pilot teaching program was carried out at Gujarat Land Society Institute of English (GLSIE), Ahmedabad.

The learners chosen for pilot program were seven learners form the senior batch of GLSIE. Those learners came from more or less the same socioeconomic background. The learners were informed about the purpose of the pilot program and the kind o activities they were going to be involved in.

The use of CSs was not taught explicitly or separately. It was encouraged and induced by allowing learners to use CSs, by the teacher using CSs in her own conversation and demonstrating the use of CSs when learners fell short of TL expression.

The use of mother tongue (MT) was not only allowed but also encouraged in the initial stages. The teacher also used MT in the beginning and gradually switched over completely to the TL and also the learners were asked to interact only in the TL in the later stages.

These activities were also observed by one more observer who was a senior researcher in the area of English Language Teaching. The researcher came to the conclusion that the outcome of the pilot program was successful. That means, the use of CSs enabled the learners to express themselves better. Moreover, it increased the learner's participation in the classroom activities which enhanced TL interaction. Besides, the task and activities (used in the pilot program) interested in the learners and they could involve learners in target language interaction. A positive change with regard to learners' language behavior was also noticed towards the end of the program. That means strategy training helps the learners to participate in TL communication effectively.

Dornyei and Thurrell (1991) conducted an empirical study on the teachability of CSs. They believed that CSs can be taught in the classroom for L2 learners explicitly as well as implicitly. In 1991 they reported their experiment on teaching some aspects of "message adjustment" and resource expansion skills. They taught:
a) Fillers
b) Going off the point (avoiding giving information) 
c) Paraphrase and circumlocution

a) Fillers

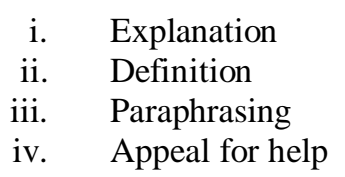

Dornyei and Thurrell (1991) used the term "fillers" to refer to hesitation devices, pauses, etc., but this term was developed further in Dornyei (1995a) and replaces by "stalling for time-gaining strategies". The latter term included different aspects that allow the speaker to think properly of the nest word or words. It gives more time for "maneuvering" and for carrying on the conversation in times of difficulty. Time-gaining, for example, give the speaker/learner a good chance to re-plan his ideas according to the situation.

These fillers or time-gaining expression are ranges from very short structure (well, I mean, actually, you know), to what are almost phrase (as a matter of fact, to be quite honest, now let me think, I'll tell you what, I see what you mean, etc.).

Dornyei and Thurrell (ibid) suggest that the use of these devices can be encouraged right from the early stages. The teacher should make his learners aware of the usefulness of fillers whenever possible.

b) Going off the point

This strategy trains the learners how to evade an answer smoothly when they do not want to, or simply cannot answer a question. Moreover, it trains them how to steer the conversation in a desired direction. This, of course, will enable the learners to control the conversation even if something unexpected occurs. An example from Dornyei and Thurrell (1991:20-21). Avoiding giving information:

The teacher addressed a student with a question that asks for specific information, for example, how old are you? The students must respond in two or three sentences without actually giving that particular information. A possible answer might be, for example, "Well, that's an interesting question. Isn't it strange how people always feel that they need to know the age of a person? I don't really think that age is important at all.

They also suggest that there should be some preparation time in the first stage of these activities. The preparation time should be decreased gradually till the learners get used to these activities.

c) Paraphrase (circumlocution)

i) Explanation

Dornyei and Thurrell (1991) suggest that the teacher could hand out a slip of paper to each student with the name of an object on each slip. Everybody in turn must try to "explain" their word to the others without actually saying what it is. Students jot down their guesses for all the words and the winner is the person whose word has been found out by the most students.

ii) Definition

Similarly, the learners can be trained to "define" objects. For example, in pairs, students are given the name of an object (e.g., car) which they must define by using relative clauses (e.g., ' A car is a vehicle in which you can travel'). Each pair in turn reads out their definition, while the other pairs check whether it is precise enough. If it is not - that is, if they can find another object that the definition suits (e.g., 'bus' in this case) they get a point and for another point they must give a more specific definition (e.g., ' a car is a small vehicle in which you can travel'). Again, this new definition is also open for discussion (Dornyei and Thurrell 1991).

iii) Paraphrase, for example:

So, you are saying that....

You mean ........ etc.

This is very useful strategy for learners to clarify what they have heard and to invite the interlocutor to help if they have misunderstood something.

iv) Interruption:

Student 1 asks a question; student 2 interrupts by asking him/her to repeat a word again, for example:

S 1: London is the Capital.....?

S 2: Sorry, can you repeat the word after the Capital?

Or what does the word 'capital' mean? Or did you say that London is the capital of....?

Saraswati (1991:117) came to the conclusion from her study which she conducted on an Indian post-doctoral research scholar at Edinburgh that:

Since communication strategies play a significant role in communication, it may be useful to build in enough challenge into course materials in order to create conditions congenial for the use of strategic competence.

Similarly, Faerch and Kasper (1983:55) indicate that:

If by teaching we also mean making learners conscious about aspects of their (already existing) behavior, it is obvious that we should teach them about strategies.

Dornyei and Thurrell (1994) believe that a given conversation course, taught directly, needs to be based on four categories of conversation skills. The following is a description of these skills: 
1. Conversational rules and structures.

2. Conversational strategies.

3. Functional and meanings in conversation.

4. Social and cultural context.

Dornyei (1995:163-164) suggests the following which can be used as guidelines for teaching CSs explicitly. These strategies can be summarized as follows:

1. Raising learner awareness about the nature and communicative potential of CSs. This can be done by making learners aware/conscious of strategies already in their repertoire, sensitizing them to the appropriated situation where these could be useful, and making them realize that these strategies could actually work. Faerch and Kasper (1986:187) quoted in Dornyei (1995:63) also emphasize the need to increase learners' "metacommunication awareness" with respect to strategy use.

1) Encourage students to be willing to take risk and use CSs; that is, to manipulate available language without being afraid of making errors.

2) Providing L2 models of the use of certain CSs through demonstration, listening materials and videos, and getting learners to identify, categorize, and evaluate strategies used by native speakers or other L2 speakers.

To sum up, teaching Communication Strategies directly or explicitly in the Saudi tertiary level teaching situation can be very useful and effective for the following reasons:

1. Saudi learners are not exposed to the real environment of the target language. Therefore, they need to be taught how to use CSs in order to solve their communication problems when occur.

2. Learners' L1 and L2 in Saudi Arabia are not cognate languages. In other words, there is a language distance between students' native language and the target language and that will not help students make successful transfer as is the case in the European languages. For example, French word "attention" /a'tensjo/ into the L2 /a'tenfn/ / as it exists in both languages with a slight difference in pronunciation.

3. There are cross -cultural differences between students' L1 and L2 and that leads in many cases to misunderstanding and communication breakdown. In fact, there are so many cultural-specific "do's and don'ts" that learners are constantly faced with in the target language.

\section{Data Collection and Methodology}

The data was collected by using a questionnaire conducted on level eight. The number of the students was 90 . Students are in their in the final year and are expected to graduate. They were selected because they can deal with the questionnaire in English.

Moreover, it is expected that their English is much better than other students in lower levels. The researcher checked students' understanding of the questionnaire before they started to answer the questions.

The questionnaire consists of eight questions; each question consists of four statements. Students are required to select the strategies they are using while communicating in the target language.

Try-out of the questionnaire

The questionnaire was tried out on five students to make sure that they have understood all the questions. Those five students were excluded while conducting the questionnaire to collect the data.

\section{DATA ANALYSIS}

\begin{tabular}{|l|l|l|l|}
\hline \multicolumn{2}{|l|}{ 1. Do you use any of the following expression when you speak English? } & Freq. & $\%$ \\
\hline \multicolumn{1}{|l|}{ Well, you know what I mean.... } & 16 & 18 \\
\hline 1 & As a matter of fact.... & 6 & 7 \\
\hline 2 & Ok, let me think... & 3 & 3 \\
\hline 4 & Well, I mean.... & 12 & 13 \\
\hline & Total & 31 & 41 \\
\hline
\end{tabular}




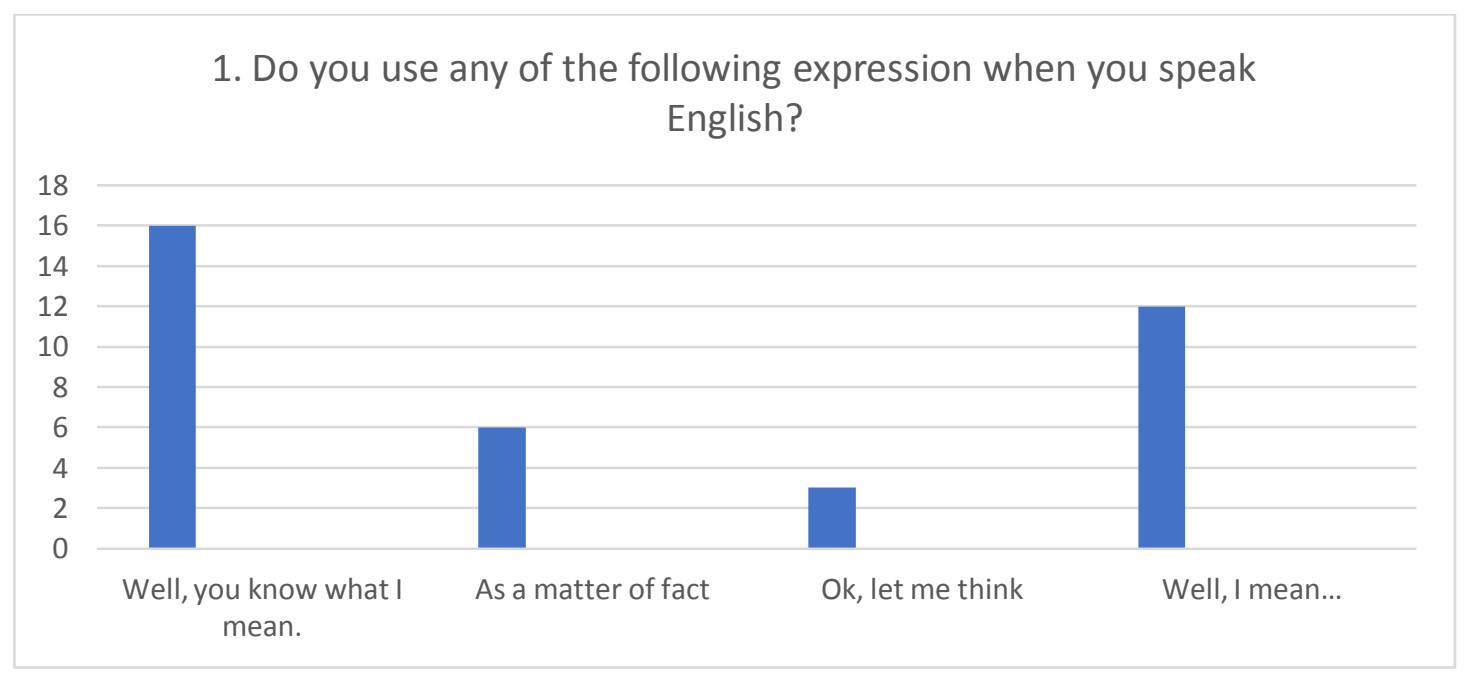

This first diagram shows that students are somehow familiar with the strategies (well, you know what I mean.... and (well, I mean.... As these two expressions exist in their mother tongue. This indicates that only few students use these strategies which help students to think and plan their ideas at the same time to show the speaker that they are thinking of the question. Very few students use "as a matter of fact" and "Ok, let met think" because they do not have something similar in their mother tongue.

\begin{tabular}{|c|c|c|c|}
\hline \multicolumn{4}{|c|}{ 2. When you speak English and come across some difficulties, what do you usually do? } \\
\hline & & Freq. & $\%$ \\
\hline 1 & Ask your listener to help you & 5 & 6 \\
\hline 2 & Change the topic & 25 & 27 \\
\hline 3 & Say something very briefly & 6 & 7 \\
\hline \multirow[t]{2}{*}{4} & Use your mother tongue. & 20 & 22 \\
\hline & Total & 32 & 36 \\
\hline
\end{tabular}

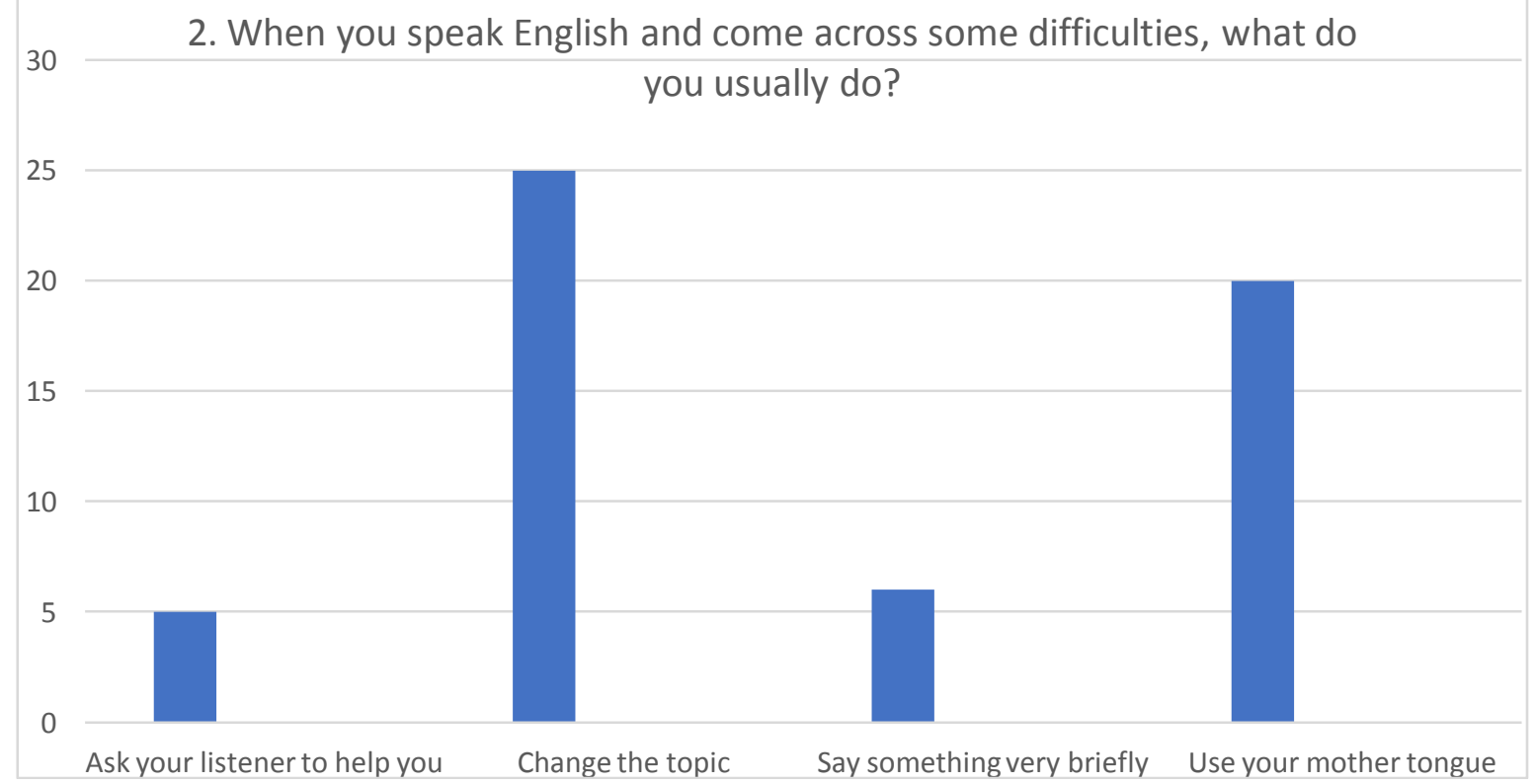

This second diagram shows that almost all students are not familiar with steering the topic in a way that they can speak and keep the channel of communication open. That means communication with the speakers of the target language breakdown immediately.

Moreover, students in many cases resort to their mother tongue to convey the message. This strategy doesn't help them especially when the speaker doesn't speak their mother tongue. 


\begin{tabular}{|l|l|l|l|}
\hline \multicolumn{2}{|l|}{ 3. Do you use any of the following expressions when you speak English? } & Freq. & $\%$ \\
\hline \multicolumn{2}{|l|}{ Can you repeat that word/sentence, please? } & 12 & 13 \\
\hline 2 & I am sorry, I didn't hear that word. & 5 & 6 \\
\hline 3 & I am sorry to interrupted you but... & 2 & 2.2 \\
\hline 4 & Well, I do agree with you but... & 0 & 0 \\
\hline & Total & 19 & 21.2 \\
\hline
\end{tabular}

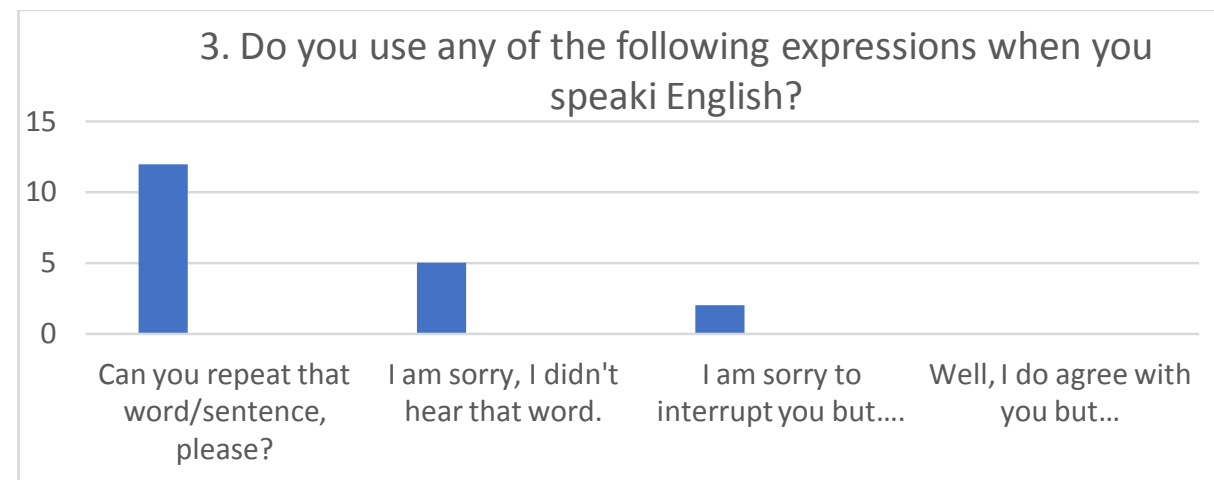

The third diagram shows that few students are only familiar with asking the speaker to repeat a word or a sentence. Similarly, a small number of students are familiar with the strategy of asking the speaker to repeat because they didn't hear the word. Apologizing for interrupting the speaker is not a very common strategy for the Saudi learners. The last strategy "Well, I do agree with you but.... is not known to the Saudi learners at all.

\begin{tabular}{|l|l|l|l|}
\hline \multicolumn{2}{|l|}{ 4. If you do not understand what your teacher is saying, which of the following do you do? } & Freq. & $\%$ \\
\hline \multicolumn{2}{|l|}{ Switch off with a feeling of disappointment. } & 25 & 28 \\
\hline 1 & Put an extra effort to understand. & 8 & 9 \\
\hline 2 & Make a note of words/sentences and ask your teacher. & 20 & 22 \\
\hline 4 & You negotiate the meaning with your teacher. & 9 & 10 \\
\hline & Total & 6 & 9 \\
\hline
\end{tabular}

4. If you do not understand what your teacher is saying, which of the following do you do?

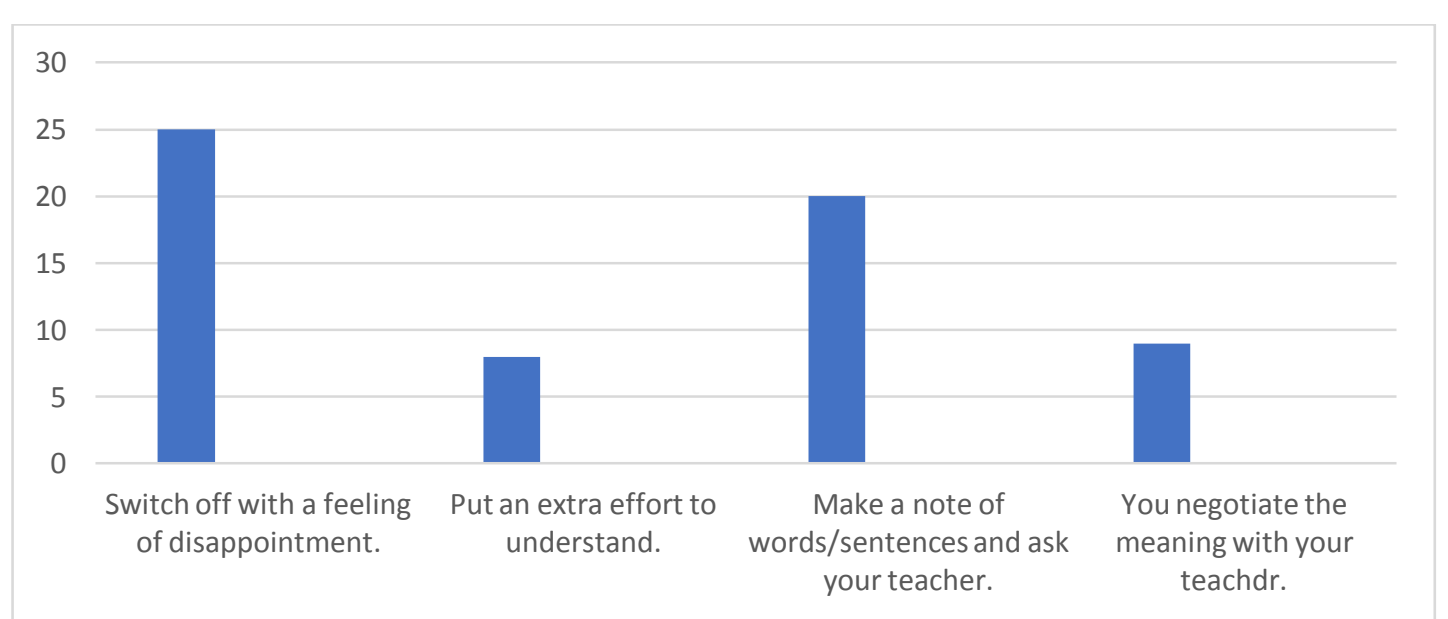

Diagram 4 shows that students feel frustrated when they can't understand the teacher and as a result, they switch off. Probably, this is the most common strategy students resort to in such situations. Therefore, students need to be trained to use more strategies such as "putting an extra effort to understand or "making notes in order to negotiate their difficulties with their teachers.

\begin{tabular}{|l|l|l|l|}
\hline \multicolumn{2}{|l|}{ 5. When speak English and you do not find the right word, what do you usually do? } & Freq. & $\%$ \\
\hline \multicolumn{2}{|l|}{ Explain that word in English. } & 2 & 2 \\
\hline 2 & Use a word that is close to that word. & 5 & 6 \\
\hline 3 & Avoid that word completely. & 15 & 17 \\
\hline 4 & Use your mother tongue. & 30 & 33 \\
\hline & Total & 52 & 58 \\
\hline
\end{tabular}


5. When speak English and you do not find the right word, what do you usually do?

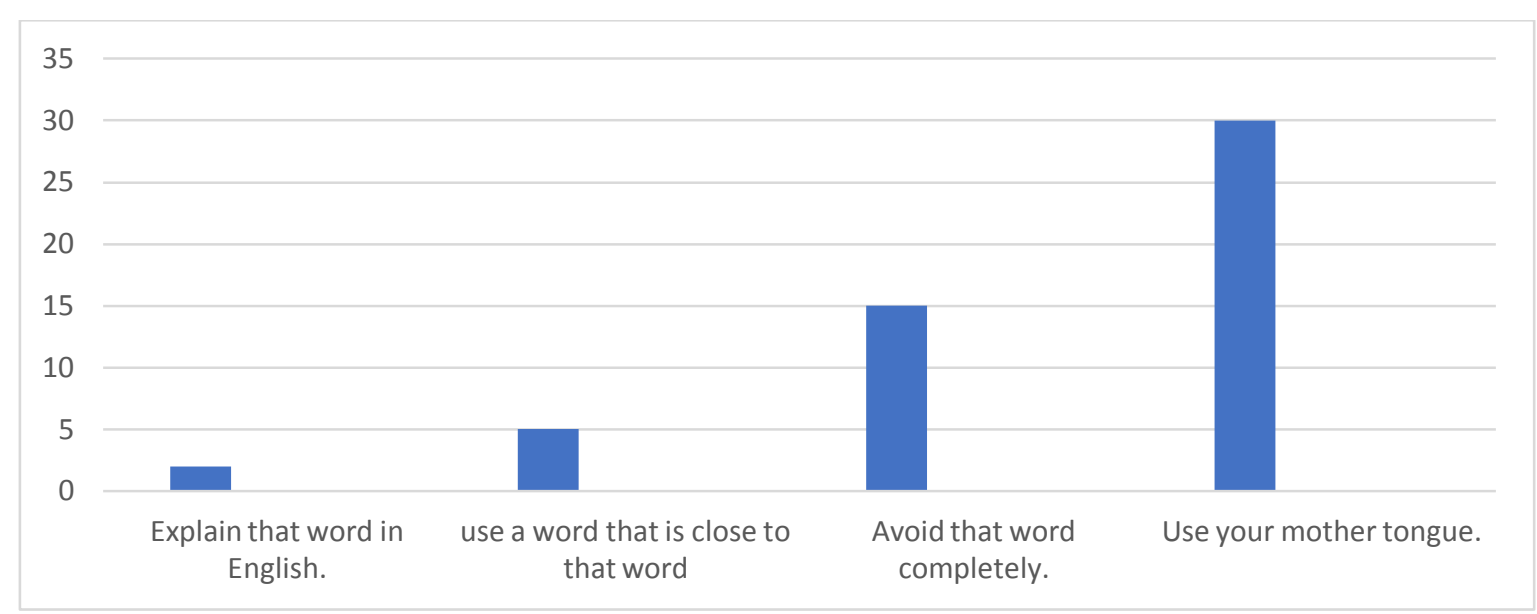

Diagram 5 Shows that Saudi students use their mother tongue more compared to $t$ all other strategies when they speak English and come across a word which they can't explain in English. This usually happens when they speak English to their teachers who share their mother tongue. However, students avoid that word when they speak to people or teachers who do not share their mother tongue. Few students explain the right word in English and some students use a close word to the needed one.

\begin{tabular}{|l|l|l|l|}
\hline \multicolumn{2}{|l|}{ 6hen you speak English do you imitate the native speakers use of: } & Freq. & $\%$ \\
\hline \multicolumn{2}{|l|}{ Gestures } & 53 & 59 \\
\hline 1 & Eye-contact & 0 & 0 \\
\hline 3 & Miming & 4 & 4 \\
\hline 4 & Fillers/pauses & 25 & 28 \\
\hline & Total & 91 & 91 \\
\hline
\end{tabular}

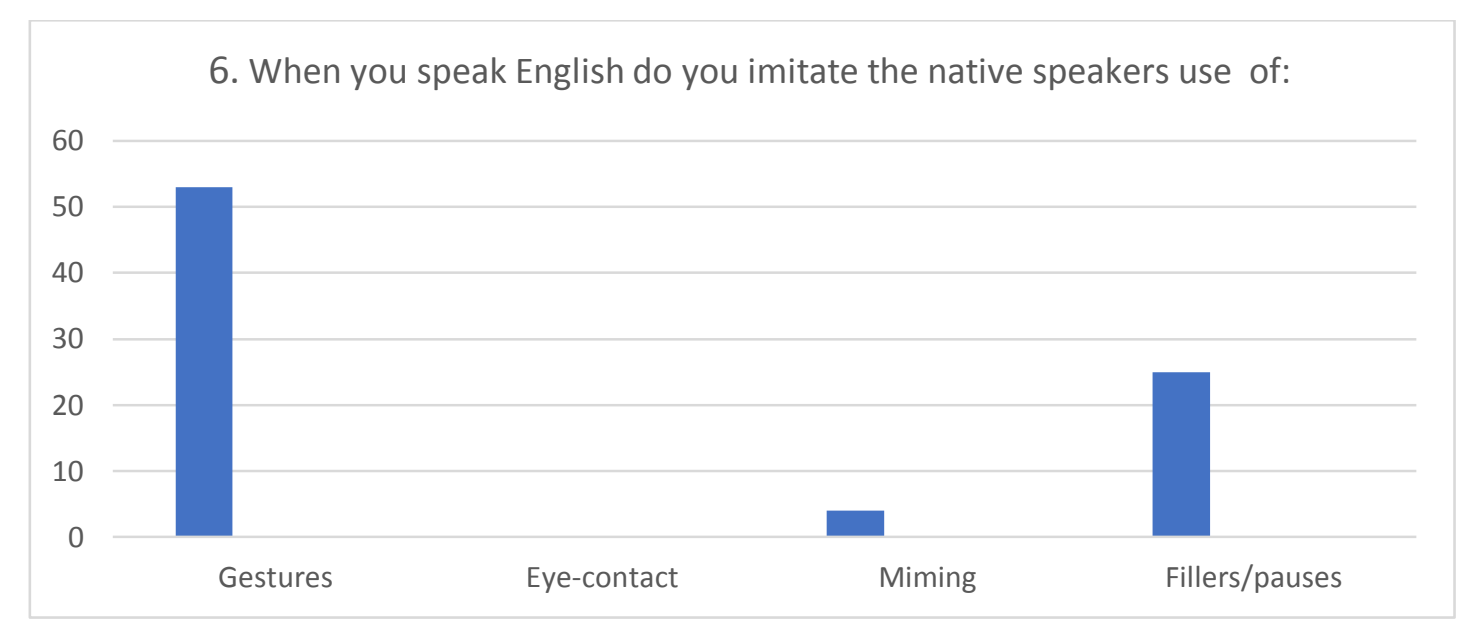

Diagram 6 shows that students can use gestures and fillers/pauses, but they usually avoid using "eye-contact and miming" and that probably that is due to the students' culture. Eye-contact is not used in Saudi students' real life communication, and that is due to some restrictions in the students' culture. As a result, students need to be trained to use these two learning strategies. Eye-contact and miming show that students are not exposed to the culture of the target language. Moreover, these strategies are not frequently used in the students' native language.

\begin{tabular}{|l|l|l|l|}
\hline \multicolumn{2}{|l|}{ 7. When you speak English what do you mainly focus on? } & Freq. & $\%$ \\
\hline \multicolumn{2}{|l|}{ Grammar } & 40 & 44 \\
\hline 2 & Pronunciation & 8 & 9 \\
\hline 3 & Meaning & 10 & 11 \\
\hline 4 & Vocabulary & 30 & 33 \\
\hline & Total & 97 & 97 \\
\hline
\end{tabular}




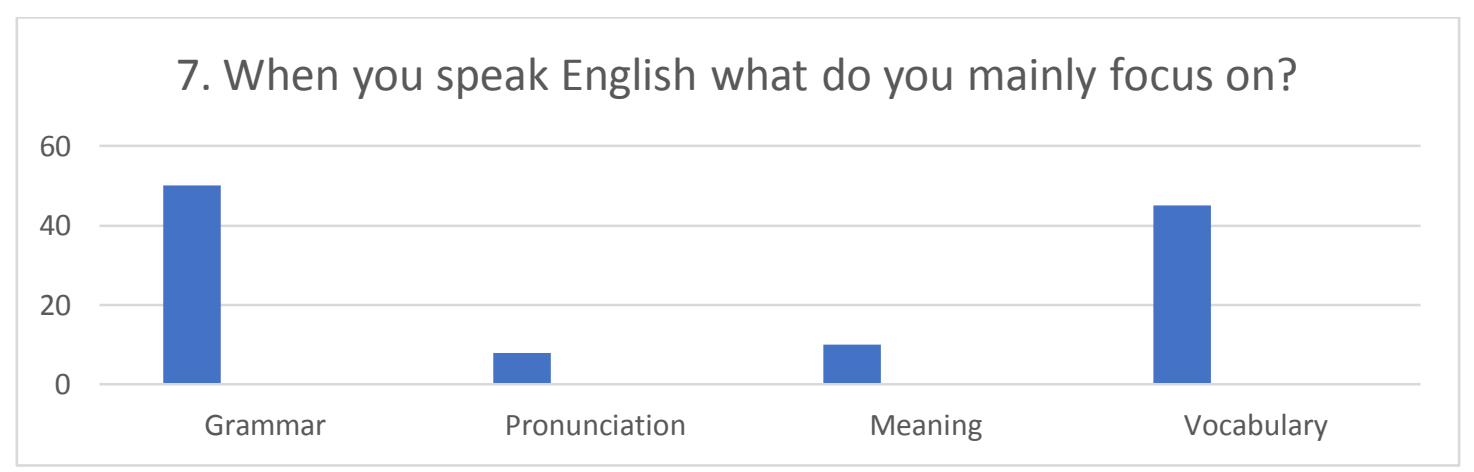

Diagram 7 shows that students focus on grammar and vocabulary more than pronunciation and meaning. Students believe that grammar and vocabulary are the most important elements to communicate in the target language. Therefore, students' grammar and vocabulary are much better compared to the other two language skills.

\begin{tabular}{|l|l|l|l|}
\hline \multicolumn{2}{|l|}{ 8. When you plan your speech in English, which of the following do you usually do? } & Freq. & $\%$ \\
\hline \multicolumn{1}{|l|}{ Think in your mother tongue and then translate into English. } & 60 & 67 \\
\hline 2 & Think in English only. & 12 & 13 \\
\hline 3 & Think in English and compare it with your mother tongue. & 15 & 17 \\
\hline 4 & Any others. & 0 & 0 \\
\hline & Total & 87 & 97 \\
\hline
\end{tabular}

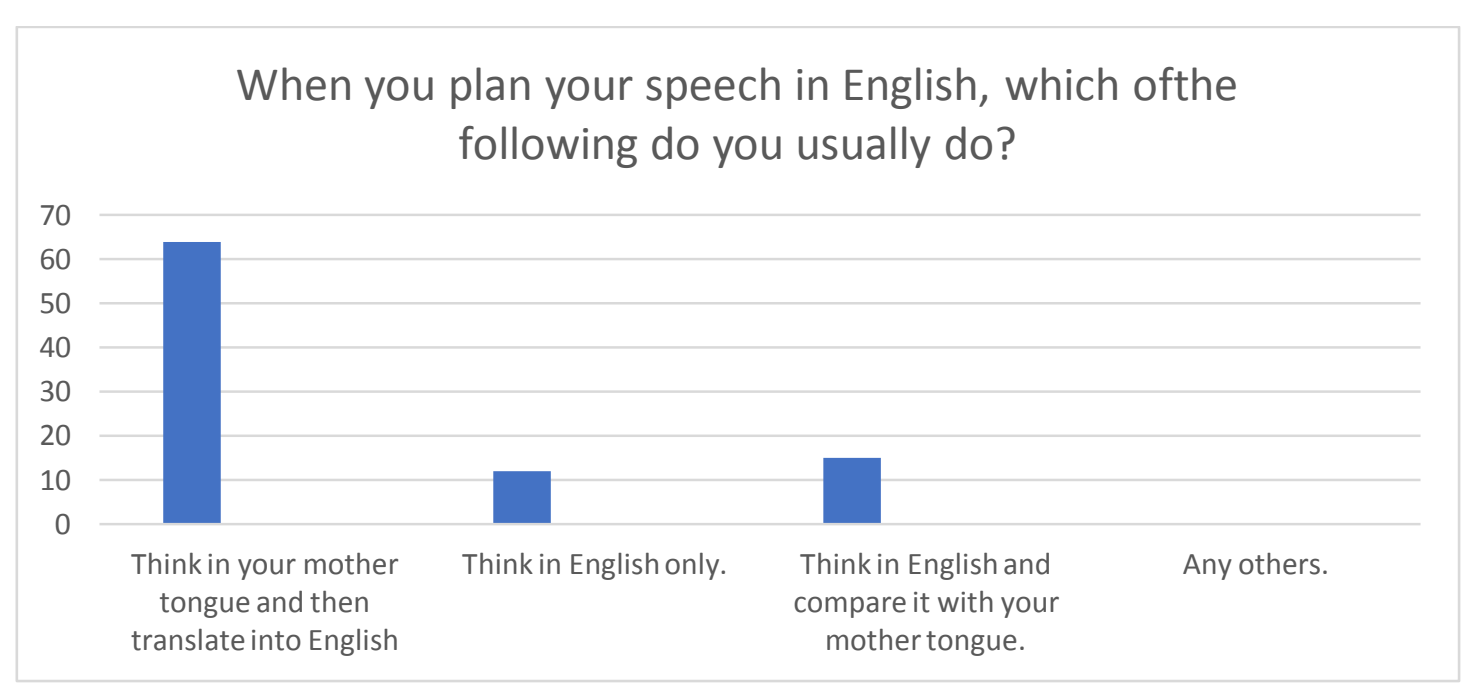

Diagram 8 shows that students mostly think in their mother tongue first and then translate into the target language. Some of them think in English but they again compare it with their mother tongue just to make sure or double check. They have developed this habit at their lower stages of learning English. Students usually try to understand everything in their mother tongue and as a result, they translate every word into their mother tongue. Very few students think in English only and do not translate what they have to say into their mother tongue.

\section{FIndings AND CONCLUSION}

The findings obtained from the Saudi tertiary level students' responses indicate that they are not aware of the usefulness of communication strategies. As a result of their lack of awareness of communication strategies such as paraphrasing, appeal for help, message adjustment etc., they resort to their first language strategies more frequently when they attempt to communicate with competent speakers of English.

Lack of Awareness of Communication Strategies

The lack of awareness of communication strategies leads to communication breakdown. This was pointed out in the students' responses to question (5) where they indicate that they avoid the required word if they cannot find it at the moment of speaking. Few students indicate that they explain that word in English or use a word which is very close in meaning to the required word but most of them indicate that they use their mother tongue equivalent to compensate for gaps in their speech.

This means that Saudi students resort to risk-avoiding strategies (by avoiding the required word or expression) more than risk-taking strategies where they have to expand their message by different means. This information was confirmed in the students' responses to question (2) where a large number of the students indicate that they change the topic when 
they feel that there are some gaps in their speech. Moreover, they indicate that they use their firs language more that they say something briefly in English or appeal for help from their interlocutor.

The following findings point out the extent to which the Saudi students' first language strategies of communication influence their tendency of using some of the target language communication strategies.

So far, the findings of the study have given us an insight into the situation of learning English at the tertiary level and the various factors which affect the Saudi students' ability to communicate with competent speakers of English in real life communicative situations. Therefore, students should be made to realize that successful oral communication not only involves how accurate the speakers are, but how clear they make themselves. In other words, speakers may utter an incorrect sentence; however, the listener can understand what the speaker intends to say. This means that speaking skills are not only some linguistic skills that can enable the speaker to communicate correctly. Therefore, Saudi students need to be aware of the components of the communicative competence in order to enable them to communicate successfully.

It is recommended that the linguistic competence should be taught implicitly whereas the functional competence should be taught explicitly during spoken English classes. This is because the findings indicate that most of the difficulties that Saudi students encounter while communicating in the target language and lead to communication breakdown result from their lack of the functional aspects of communicative competence. That means Saudi students lack the knowledge of the sociocultural rules of the target language which help them adjust themselves in a specific situation. Similarly, they lack strategic competence which gives the speakers an opportunity to express themselves with the amount of the language they have already mastered.

Therefore, Saudi students need to be trained how to resort to risk-taking strategies which help students to expand their message they want to convey without resorting to their first language equivalents.

Moreover, Saudi students need a course that focuses on the conversational skills based on the guidelines which were suggested by Dornyei and Thurrell (1994) as follow:

1. Conversation rules and structures; openings, turn taking, interruption, topic shifting, adjacency pairs and closing.

2. Conversational strategies: message adjustment or avoidance, paraphrasing, approximation, appeal for help, asking for repetition, asking for clarification, using interpretive summary, checking and use of fillers.

3. Functions and meanings in conversation:

a) Languages function such as making suggestions and asking for information.

b) Indirect speech acts. These are linguistic forms that include an action or a function. For example, could you open the window, please?

It is not a real question but rather a request to open the window.

c) Same meaning - different meaning. This issue deals with the surface and the real meaning of the utterance. For example, the compliment 'What a nice car you have! Might mean I did not know that you are so rich or hope you will let me borrow it next Sunday.

4. Social and cultural context including; participant variables (status) the social situation, the social norms of appropriate language use formal/informal, and cross-cultural differences.

These guidelines should be taken into consideration when designing/selecting a new spoken language courses at the tertiary level in order to enable Saudi students to overcome their difficulties they encounter when they are put in real communicative situation with competent speakers of English.

Lack of Exposure to the Target Language and its Culture

Findings indicate that Saudi learners of English are not exposes to the target language and its culture. Moreover, they do not have sufficient practice in the class which may compensate for their lack of exposure. However, students should be encouraged to communicate with competent speakers of English. Moreover, they should be given more opportunity to work in 'groups' and 'pairs' as that can help them develop their abilities to speak instead of making them wait for their turns to speak in the classroom.

At the same time, teachers should find some resources which can help their students to communicate in real communicative situations and also enrich their knowledge of the culture of the target language. For example:

1) Encouraging their students to communicate in English inside and outside the classroom.

2) Encouraging their students to visit the ELP center in the English Department where they can meet native speakers of English and communicate with them.

3) Watching some videos and programs which focus on the culture of the target language.

However, the social distance may cause breakdown of communication and misunderstanding and therefore teachers try to help students to overcome this problem. For example, they can teach some cultural issues explicitly especially 
where students might have problems as a result of the cross-cultural differences. These cultural differences should be introduced in small doses, because some students may become defensive towards the culture of the target language.

\section{REFERENCES}

[1] Al Alawi, R. A. (2016). "Communication Strategies used by Omani EFL students:" Pyrex Journal of English and Literature Vol 2 (1) pp. 001-011 January, 2016 http://www.pyrexjournals.org/pjel Copyright @ 2016 Pyrex Journals.

[2] Bialystok, E. (1990). Communication Strategies: A Psychological Analysis of Second Language Use. Oxford: Basil Blackwell

[3] Buch, A. (1989). "Developing the Ability to Use Communication Strategies in Adult ESL Learners. Unpublished M. Litt. Thesis," Hyderabad CIEFL.

[4] Canale, M. and Swain, M. (1980). "Theoretical Bases of Communicative Approach to Second Language Teaching and Testing". Applied Linguistics, Vol. 1, 1-47.

[5] CELCE - MURCIA, M. A. R. I. A. N. N. E., Dörnyei, Z., \& Thurrell, S. (1997). Direct approaches in L2 instruction: a turning point in communicative language teaching? TESOL quarterly, 31(1), 141-152.

[6] Chen Si-Qing. (1990). "A Study of Communication Strategies in Interlanguage Production by Chinese EFL Learners", Language Learning, 6.

[7] Chomsky, N. (1965). Aspects of the Theory of Syntax. Cambridge, Mass: MIT Press.

[8] Corder, S. P. (1983). Strategies of Communication," in C. Faerch and G. Kasper (eds.) Strategies in Interlanguage Communication. London: Longman.

[9] Dornyei, Z. and Scott, M. L. (1997). "Communication Strategies in a second language: Definitions and taxonomies". Language Learning, 47, $173-210$.

[10] Dornyei, Z. (1995). "On the Teachability of Communication Strategies" TESOL Quarterly, Vol. 29, 55 - 85.

[11] Dornyei, Z. (1991). "Strategic competence and how to teach it", ELT Journal, 01/01.

[12] Dornyei, Z. and Thurrell, S. (1994). "Teaching Conversational Skills Intensively: Course Content and Rationale." English Language Journal, Vol. 48. 40 - 49.

[13] Dornyei, Z. and Thurrell, S. (1991). "Strategic Competence and How to Teach It". English Language Teaching Journal, Vol. 45/1 1991.

[14] Ellis, R. (1994). The Study of Second Language Acquisition. Oxford: Oxford University Press.

[15] Faerch, C. and Kasper, G. (1983a). Strategies in Interlanguage Communication. London: Longman.

[16] Faucette, P. (2001). "A pedagogical perspective on communication strategies: Benefits of training and an analysis of English language teaching materials". Second Language Studies, 19 (2), 1-40.

[17] Hymes, D. (1972) "On Communicative Competence," in Pride and Holmes (eds). Sociolinguistics, Harmondsworth, U. K. Penguin Books, $141-161$.

[18] Nakatani, Y. (2010). "Identifying strategies that facilitate EFL learners' oral communication: A classroom study using multiple data collection procedure". The Modern Language Journal, pp. 116 - 136. Language: English. DOI: 10.1016/j.sbspro.2012.05.196, Database: ScienceDirect.

[19] Littlewood, W. (1981). Communicative Language Teaching: An Introduction. Cambridge: Cambridge University Press.

[20] Nanda Poulisse. (1996). Strategies. Investigating Second Language Acquisition (pp. 135164). https://doi.org/10.1515/9783110812831.135.

[21] Nunan, D. (1989). Designing Tasks for the Communicative Classroom. Cambridge: Cambridge University Press.

[22] Nunan, D. (1987). "Communicative Language Teaching: Making it Work." English Language Teaching Journal, Vol. 41.136 -145 .

[23] O'Malley, J and Chamot, J. (1990). Learning Strategies in Second Language Acquisition, Cambridge: Cambridge University Press.

[24] O'Mally, J. (1987). "The Effects of Training in the Use of Learning Strategies on Acquiring English as a Second Language". In Wenden and Rubin (eds.) Learning Strategies in Language Learning. Englewood Cliff, N. J.: Prentice Hall 78 - 98.

[25] O'Mally, J. and Chamot, A. (1990). Learning Strategies in Second Language Acquisition. Cambridge: Cambridge University Press.

[26] Oxford, R. L. (1990). Language Learning Strategies: What Every Teacher Should Know. Boston; Heinle and Heinle.

[27] Poulisse, N. (1994). "Communicative Strategies in a Second Language," in Asher et al (eds) The Encyclopedia of Language and Linguistics. Oxford: Pergamon Press Vol. 2, 620 - 624.

[28] Paribakht, T. (1985). " Strategies Competence and Language Proficiency". Applied Linguistics, Vol. 6. 132 - 146.

[29] Raed Latif Ugla, Mohamad Jafre Zainol Abidin, Mohammed Najim Abdullah. (2019). "The influence of proficiency level on the use and choice of L1/L2 communication strategies used by Iraqi EFL students", International Journal of Evaluation and Research in Education (IJERE).

[30] Rababah, G. (2016). "The Effect of Communication Strategies Training on the Development of EFL Learners' Strategies Competence and Oral Communicative Ability". J Psycholinguist Res. (2016) 45:625-651.

[31] Rababah, G. (2005). "Strategic competence in an ELT syllabus". ITL: International Journal of Applied Linguistics, 145-146, 145-164.

[32] Richard's, J. (1992). The Language Teaching Matrix. New York: Cambridge University Press.

[33] Rost, M. and Ross, S. (1991). "Learner Use of Strategies of Interaction: Typology and Teachability" Language Learning, Vol. $14,225-173$.

[34] Saraswati, V. (1991). "The Influence of Context Variables in Strategies of Communication in English: A Case Study," In V. Parakasam and S.V. Parasher (eds.) Linguistics at Large. Papers in General Applied Linguistics. Hyderabad: Booklinks Corporation.

[35] Savignon, S. (1972). "Communicative Competence: An Experiment in Foreign Language Teaching". Philadelphia: Center for Curriculum Development. 
[36] Savignon, S. (1983). Communicative Competence: Theory and Classroom Practice. Reading, MA: Addison - Wesley Publishing Company.

[37] Selinker, L. (1972). "Interlanguage" International Review of Applied Linguistics, Vol. 10, 201 - 231.

[38] Tarone, E., Cohen, A. Dumas, G. (1983). "A Closer Look at Some Interlanguage Terminology: A Framework for Communication Strategies". Working Papers on Bilingualism, Vol. 9, 76 -90.

[39] Tarone, E. (1976). "Conscious Communication Strategies in Interlanguage: A Process Report," in H. Brown and R. Crymes (eds.) On TESOL 77. Washington, D. C., 194-203.

[40] Varadi, T. (1992). "Communication Strategies: A Psychological Analysis of Second Language Use and the Use of Compensatory Strategies by Dutch Learners of English". Applied Linguistics, Vol. 13, $434-440$.

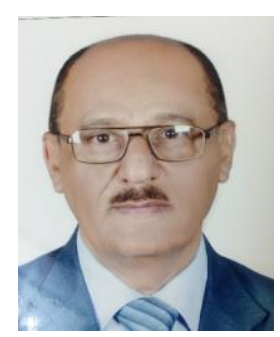

Rafiq Al-Shamiry is currently an associate professor of English Language Teaching (ELT) at the Faculty of Languages and Translation, King Khalid University, Kingdom of Saudi Arabia. He has taught English for 15 years in Ibb University, Yemen. He has worked for the Ministry of Education as a chief inspector of English for 10 years. He has obtained his post graduate diploma in Applied Linguistics, Moray House, College of Education (UK). His Master degree in Applied Linguistics, Leeds University, School of Education (UK). His Ph.D. in Applied Linguistics, C.I.E.F.L. Hyderabad, India. His interests are applied linguistics issues in language teaching. 